\title{
ВЫСОКОЭФФЕКТИВНЫЕ СОЛНЕЧНЫЕ ЭЛЕМЕНТЫ НА ГЕТЕРОСТРУКТУРАХ
}

\author{
${ }^{1}$ Мустафаев А.Г., \\ ${ }^{2}$ Мустафаев Г.А. \\ ${ }^{1}$ ГАОУ ВО «Дагестанский государственный университет \\ народного хозяйства», г. Махачкала, Россия \\ ${ }^{2}$ ФГБОУ ВО «КБГУ», г. Нальчик, Россия
}

Наиболее эффрективным и проверенным в условиях длительной эксплуатации способом получения электричества из солнечной энергии является фотоэлектрическое прямое преобразование, которое реализуется в полупроводниковых солнечных элементах. В работе рассмотрен способ увеличения эффективности фотопреобразования солнечных элементов, на основе полупроводниковых квантово-размерных гетероструктур.

Ключевые слова: солнечный элемент, фотоэлектрический преобразователь, $\mathrm{A}^{\mathrm{III}} \mathrm{B}^{\mathrm{V}}$, полупроводниковая структура, квантовый эффект.

Основным направлением развития солнечной энергетики является уменьшение удельной стоимости солнечных элементов, зависящей от стоимости производства солнечным элементов электричества и отдаваемой им мощности $[1,2]$. Значительная часть солнечных элементов производится на основе кремния. При этом коэффициент полезного действия (КПД) кремниевых солнечных элементов не превышает 30\% (за исключением лабораторных образцов) [3]. Эффективность преобразования солнечной энергии можно увеличить, расширив спектр поглощаемых фотонов используя структуры на квантово-размерных эффектах. Важным преимуществом солнечных элементов на основе гетероструктур по сравнению со структурами на основе кремния являются больший КПД, высокая температурная и радиационная стабильность, а также высокая эффективность преобразования солнечного излучения [4].

Солнечные элементы (СЭ) использующие квантово-размерный (КР) эффект, были изготовлены на основе структур $\mathrm{AlGaAs} / \mathrm{GaAs}$, содержащих серию потенциальных ям. На рис. 1 представлена энергетическая диаграмма квантово-размерного солнечного элемента с одинаковой шириной потенциальных ям. Ширину запрещенной зоны $\mathrm{E}_{\mathrm{a}}$, и соответственно спектр поглощения, можно изменять соответствующим выбором ширины потенциальной ямы $\mathrm{L}_{\mathrm{z}}$ и ширины барьера $\mathrm{L}_{\mathrm{b}}$. 


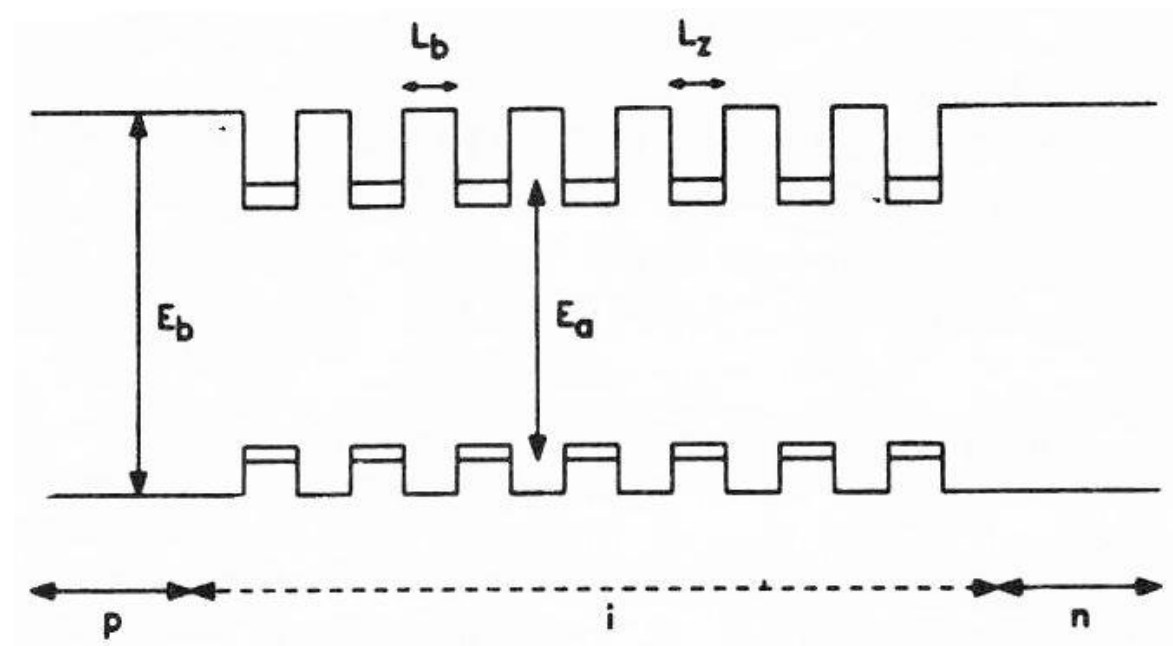

Рис. 1. Энергетическая диаграмма квантово-размерного солнечного элемента

Предел КПД такого солнечного элемента может превышать 50\%, в то время как КПД обычных солнечных элементов на основе GaAs не превышает $40 \%$ (рис. 2). Диапазон минимальных энергий, которые могут поглощаться, можно изменять, меняя ширину каждой последующей потенциальной ямы.

Структура, представленная на рис. 1 образует область собственной проводимости ріn-диода. Путем подбора параметров $\mathrm{L}_{\mathrm{z}}, \mathrm{L}_{\mathrm{b}}$, состава барьерного материала и количества потенциальных ям можно достигнуть более высокого КПД фотопреобразования. Параметры, определяющие поглощение и параметры, определяющие напряжение холостого хода, можно оптимизировать независимо друг от друга, тогда как в обычных СЭ и поглощение и напряжение холостого хода определяются шириной запрещенной зоны объемного материала.

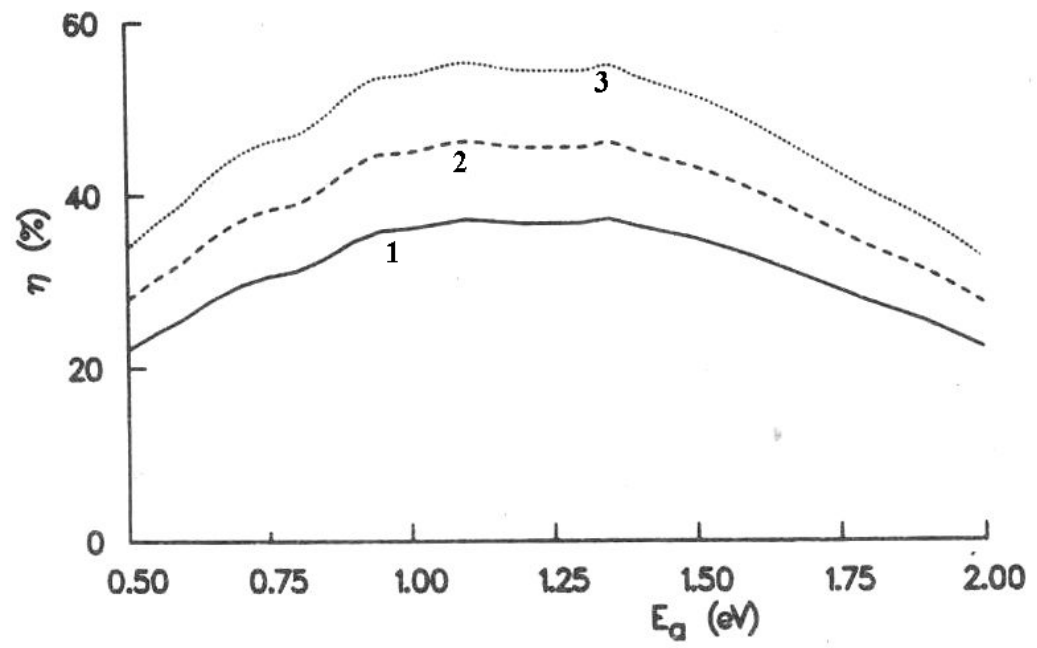

Рис. 2. Зависимость КПД солнечного элемента от ширины запрещенной зоны $\mathrm{E}_{\mathrm{a}}$ : 1- обычный СЭ с одним потенциальным барьером; 2 - СЭ, при ширине $\mathrm{E}_{\mathrm{b}}$, большей $\mathrm{E}_{\mathrm{a}}$ на 20\%; 3- СЭ, при ширине $\mathrm{E}_{\mathrm{b}}$, большей $\mathrm{E}_{\mathrm{a}}$ на $40 \%$.

Из рис. 2 видно, что КР СЭ более эффективен, чем СЭ обычной конструкции, если $\mathrm{E}_{\mathrm{b}}$ превышает $\mathrm{E}_{\mathrm{a}}$ более чем на $20 \%$. 
В обычных СЭ одним из главных факторов, ограничивающих КПД, являются потери, возникающие при поглощении фотонов с энергией, большей, чем ширина запрещенной зоны полупроводника барьерной области $[5,6]$. В КР СЭ пик поглощения, при комнатной температуре соответствующий минимальному уровню энергии, в два раза выше, чем уровень поглощения в сплошном полупроводнике. Поэтому изменяя ширину каждой последующей потенциальной ямы, можно обеспечить такой режим работы КР СЭ, при котором максимально возможное количество актов поглощения осуществляется на этих пиках, т.е. на границе запрещенной зоны. Для этих целей использовались структуры арсенида галлия-индия $\left(\mathrm{Ga}_{0.65} \mathrm{In}_{0.35} \mathrm{As}\right)$ которые перекрывают диапазон значений ширины запрещенной зоны, представляющих практический интерес для использования в СЭ. Согласование решеток GaAs и $\mathrm{Ga}_{0.65} \mathrm{In}_{0.35} \mathrm{As}$ обеспечивается использованием слоя $\mathrm{Al}_{0.3} \mathrm{Ga}_{0.7} \mathrm{As}$ (рис. 3). При этом кристаллические решетки сопрягаются плавно, без возникновения дислокаций несоответствия.

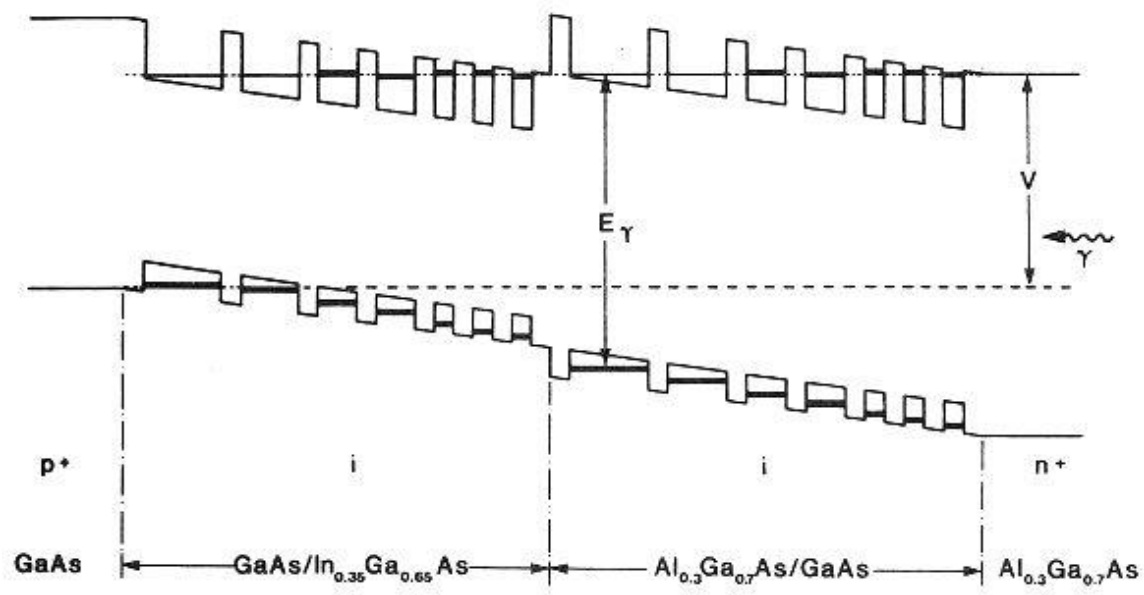

Рис. 3. Энергетическая диаграмма квантово-размерного солнечного элемента

В выбранной геометрии КР СЭ ширина потенциальных ям выбирается таким образом, чтобы уровни электронов являлись уровнями резонансного туннелирования при рабочих смещениях. Геометрия структуры должна обеспечить минимальную рекомбинацию в і-областях КР СЭ. Главной проблемой в такой геометрии является сохранение условий резонансного туннелирования путем изменения ширины потенциальных ям, тогда как высокая степень поглощения обеспечивается достаточным количеством потенциальных ям. 


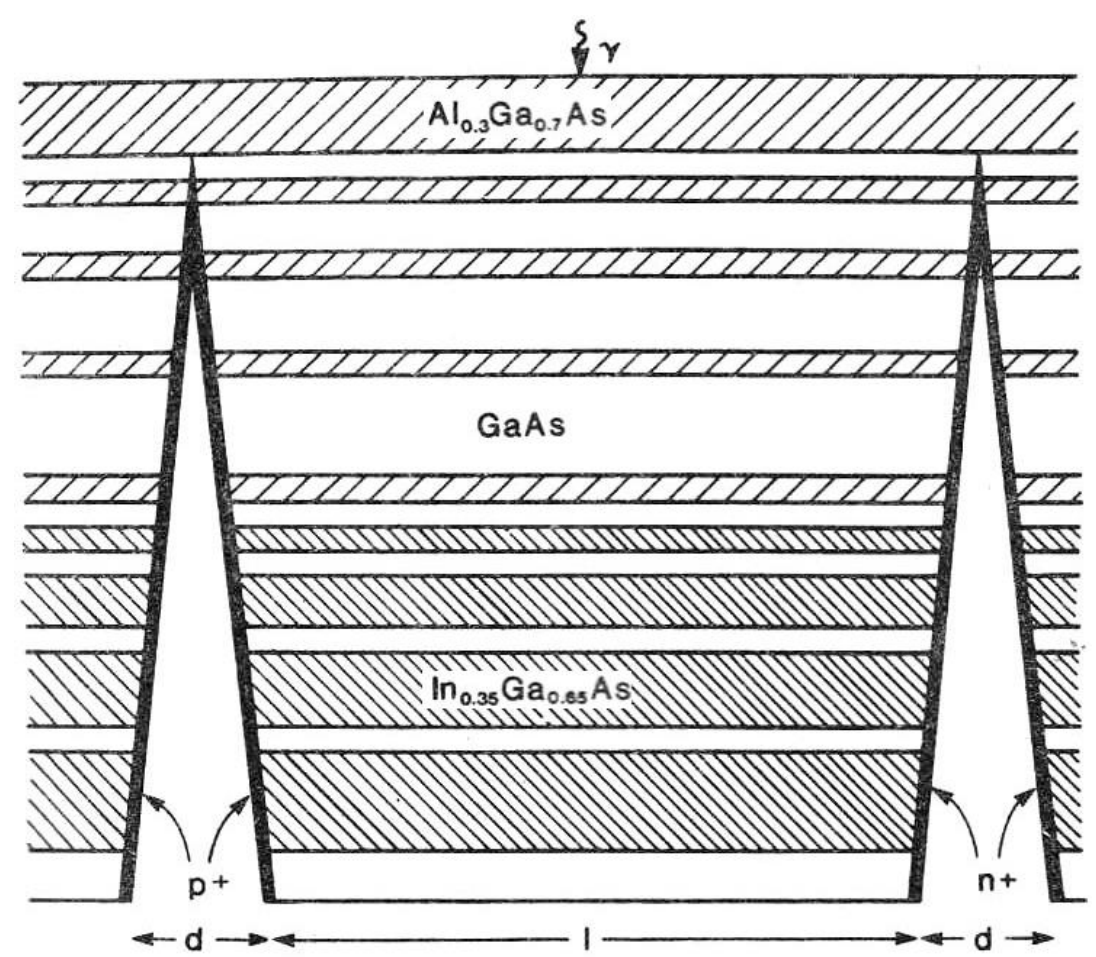

Рис. 4. Геометрическая структура квантово-размерного солнечного элемента

В направлении, параллельном потенциальной яме, подвижность электронов при комнатной температуре для рассмотренных выше материалов сравнительно велика и составляет $9112 \mathrm{~cm} /$ В.с. Выращенная методом молекулярно лучевой эпитаксии область і-проводимости является слаболегированной $\left(10^{14} \mathrm{~cm}^{-3}\right)$ и, следовательно, время жизни дырок велико. Разделение зарядов и собирание тока в направлении, параллельном потенциальной яме, может быть реализовано с помощью канавочных контактов, как показано на рис. 4. В этой геометрии оптимизация поглощения производится изменением ширины потенциальной ямы с глубиной слоя. Рассматриваемая структура эквивалентна большому числу элементов, включенных параллельно. При этом напряжение холостого хода, равно усредненному значению напряжения каждого элемента, а ток равен сумме токов всех элементов.

Эффективную ширину запрещенной зоны, определяющей поглощение фотонов, можно изменять путем варьирования ширины потенциальной ямы и состава слоев. В отличие от обычных СЭ, в рассмотренном КР СЭ существует возможность независимо оптимизировать ток и напряжение СЭ.

\section{Список литературы}

1. Алфёров Ж. И., Андреев В. М., Румянцев В. Д. Тенденции и перспективы развития солнечной фотоэнергетики // Физика и техника полупроводников. 2004. Т. 38, вып. 8. С. 937-948.

2. Weber E.R., Glunz S., Henning H.M., Palzer A., Schindler R. Low-Cost Harvesting of Solar Energy: The Future of Global Photovoltaics // Green 
Photonics and Electronics. NanoScience and Technology. Springer, 2017, pp.215261.

3. Apostoleris H., Stefancich M., Chiesa M. Concentrating Photovoltaics (CPV): The Path Ahead, Springer, 2018, 68p.

4. Takeda Y. Requisites for Highly Efficient Hot-Carrier Solar Cells // Quantum Dot Solar Cells, 2013, vol. 15, pp.187-232.

5. Cheong J.S., Baharuddin A.N.A.P., Ng J.S., Krysa A.B., David J.P.R. Absorption coefficients in AlGaInP lattice-matched to GaAs // Solar Energy Materials and Solar Cells, vol. 164, 2017, pp.28-31.

6. Tiwari B., Hossain M.J., Bhattacharya I. GaP/InGaAs/InGaSb triple junction current matched photovoltaic cell with optimized thickness and quantum efficiency // Solar Energy, vol. 135, 2016, pp.618-624. 